\title{
Характеристики катионообменной мембраны МК-40 при электродиализе растворов минеральной соли и аминокислоты
}

\author{
Харина А.Ю., Елисеева Т.В. \\ ФГБОУ ВО «Воронежский государственный университет», Воронеж
}

Поступила в редакцию 05.01.2017 г.

\begin{abstract}
Исследованы вольт-амперные и транспортные характеристики катионобменной мембраны МК-40 в процессе электродиализа смешанных растворов минеральной соли и различных $\alpha$-аминокислот, отличающихся строением бокового радикала. Установлено влияние типа бокового радикала на массоперенос аминокислоты и транспорт катионов минеральной соли через катионобменную мембрану. Выявлено, что увеличение гидрофобных свойств аминокислот, адсорбирующихся на поверхности мембраны, приводит к увеличению ее гидрофобности, что сопровождается большим вкладом электроконвекции в интенсивных токовых режимах электродиализа растворов, содержащих аминокислоты.

Ключевые слова: аминокислота, хлорид натрия, электродиализ, катионообменная мембрана, вольт-амперная характеристика, массоперенос
\end{abstract}

\section{Cation-exchange membrane MK-40 characteristics in electrodialysis of mixed solutions of mineral salt and amino acid}

\author{
Kharina A.Yu., Eliseeva T.V. \\ Voronezh State University, Voronezh
}

\begin{abstract}
The electrochemical and transport characteristics of cation-exchange membranes MK-40 which are used in amino acids (AA) solutions demineralization by electrodialysis are studied. The peculiarities of current-voltage curves and solution components mass transfer in electrodialysis of mixed solutions containing organic ampholyte and mineral salt are revealed.

The experiments have been carried out in a multisection electrodialyzer with heterogeneous anionexchange membranes MA-41 and cation-exchange membranes MK-40 manufactured by "»Shchekinoazot» Ltd, Russia. The electrodialysis device has $\mathrm{AgCl}$ electrodes placed on the both sides of the cation-exchange membrane for current-voltage curves registration. The behavior of various amino acids such as alanine (Ala), phenylalanine (Phe) and tryptophan (Trp) is compared in this study.

Current-voltage curves and transport characteristics of cation-exchange membrane MK-40 are measured in electrodialysis of mixed solutions of mineral salt $-\mathrm{NaCl}(0.01 \mathrm{M})$ and amino acid $(0.02 \mathrm{M})$. The influence of AA side group on sodium ions and amino acids transport through the cation-exchange membrane MK-40 is studied.

The ionic composition of organic ampholyte solutions depends on $\mathrm{pH}$. When the $\mathrm{pH}$ of solution is close to an amino acid pI (isoelectric point), the fraction of AA cations and anions is very low in a dilute solution and their influence on limiting current density value is slight so $i_{\text {пред }}$ does not change significantly in mixed solution $(\mathrm{NaCl}+\mathrm{AA})$ in comparison with $\mathrm{i}_{\text {пред }}$ in individual $\mathrm{NaCl}$ solution. However, the solution $\mathrm{pH}$ changes during electrodialysis at the overlimiting conditions lead to the formation of monopolar ions of amino acids. They are the additional current carriers. One can find a difference in sodium ions fluxes through
\end{abstract}


MK-40 and current-voltage curves of these membranes in the overlimiting mode making the comparison of individual $(\mathrm{NaCl})$ and mixed $(\mathrm{NaCl}+\mathrm{AA})$ solutions.

The increase of membrane surface hydrophobicity due to amino acid's side group properties leads to the intensification of electroconvection contribution in overlimiting mass transfer. In accordance with hydrophobicity growth in a row: Ala $<$ Phe $<\operatorname{Trp}$ the plateau length of current-voltage curve of the membrane MK-40 decreases.

The results of this work can be used as electrochemical bases for amino acid solutions demineralization.

Keywords: amino acid, sodium chloride, electrodialysis, cation-exchange membrane, currentvoltage curve

\section{Введение}

В производстве аминокислот микробиологическим синтезом проведение обессоливания их растворов методом электродиализа представляется весьма перспективным. Однако в электромембранной системе, содержащей минеральную соль и аминокислоту, может протекать ряд нежелательных процессов. Среди них диффузия и электроосмотический транспорт органического амфолита в секции концентрирования, а также специфические взаимодействия между структурными фрагментами ионообменных мембран и органического амфолита, вызывающие в некоторых случаях отравление ионообменного материала. Концентрационная поляризация приводит к протеканию реакции диссоциации воды на межфазной границе мембрана - раствор, изменяющей $\mathrm{pH}$ растворов амфолитов, в результате чего биполярные ионы аминокислоты перезаряжаются в монополярные катионы и анионы. Сложный ионный состав смешанных растворов органического амфолита и минеральной соли при $\mathrm{pH}$, существенно отличном от изоэлектрической точки аминокислоты, осложняет очистку растворов аминокислот их дополнительными потерями, возникающими даже когда степень обессоливания невелика. Важное значение для проведения эффективной деминерализации имеет оценка поведения ионообменных мембран в рассматриваемых системах.

Цель настоящей работы состоит в исследовании характеристик катионообменных мембран МК-40, используемых в процессе электродиализа растворов различных нейтральных $\alpha$-аминокислот в смеси с $\mathrm{NaCl}$. Изучение вольтамперных характеристик (BAX) мембран, массопереноса аминокислоты и соли через исследуемые мембраны, изменения $\mathrm{pH}$ растворов секций концентрирования и обессоливания в зависимости от плотности тока при электродиализе выявляет особенности процессса деминерализации растворов данного типа органических амфолитов.

\section{Эксперимент}

Исследование электрохимических и массообменных характеристик катионообменных мембран проведено при разделении органического амфолита -

одной из нейтральных $\alpha$-аминокислот: фенилаланина<smiles>NC(Cc1ccccc1)C(=O)O</smiles>

(Phe),

аланина $\mathrm{NH}_{2}$ (Ala) или триптофана нN - хлорида натрия $(0.01 \mathrm{M})$ в модельных растворах в процессе электродиализа. Концентрация Phe, Trp или Ala в растворах -0.02M. 
В многокамерном электродиализном аппарате использованы гетерогенные сульфокислотные катионообменные мембраны МК-40 и высокоосновные анионообменные мембраны МА-41, изготовленные ООО «Щекиноазот», Россия. Материал камер лабораторного аппарата для электродилиза - органическое стекло, материал анода - платина, катода - нержавеющая сталь. Площадь поперечного сечения секции электродиализатора равна $1 \mathrm{~cm}^{2}$. Высота канала электродиализатора 20 см. Монополярные мембраны МК-40 и МА-41 служат разделителями на секции электродиализного аппарата. В секцию (4) деионизации подавался смешанный раствор аминокислоты и минеральной соли. Через секции концентрирования $(3,5)$ прокачивался раствор $\mathrm{NaCl}(0.01 \mathrm{M})$. В секции 1,2,6,7 поступал раствор сульфата калия $(0.1 \mathrm{M})$. Линейная скорость течения раствора составила $3.3 \cdot 10^{-4} \mathrm{M} / \mathrm{c}$. Исследования проводились в гальваностатическом режиме. Вольт-амперные характеристики мембран регистрировались с помощью хлоридсеребряных электродов, размещенных с двух сторон на расстоянии от поверхностей катионообменной мембраны 0.2 мм. Фиксирование достижения предельной плотности тока в работе осуществлялось при обработке ВАХ мембран, зависимостей потоков аминокислоты через мембраны от плотности тока и при использовании методики несимметричной конценрационной поляризации [1]. На рисунке 1 изображена лабораторная ячейка для электродиализа.

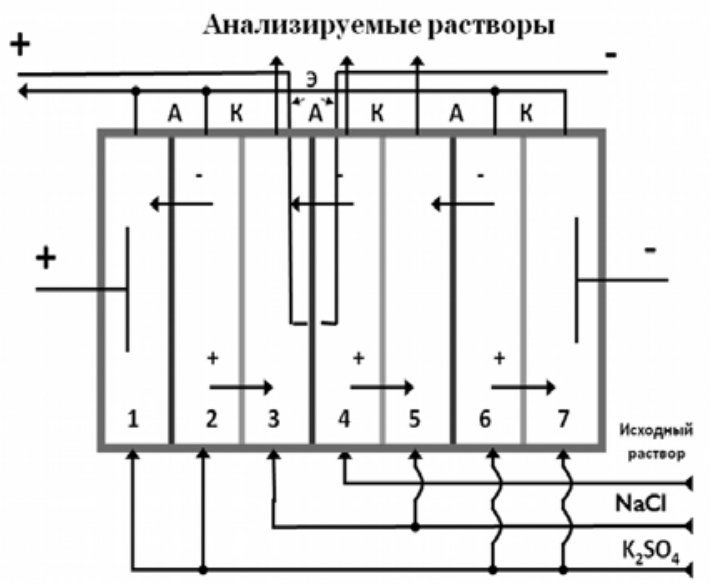

Рис. 1. Схематическое изображение ячейки с анионообменными (А) и катионообменными (К) мембранами, Э - хлоридсеребряные электроды

В работе осуществлялся контроль перераспределения ионов в растворах камер 3,4,5 под действием электрического тока. Количественное определение алкилароматической и гетероциклической аминокислот проводилось методом спектрофотомерии [2]. Содержание алифатической аминокислоты аланина в растворах измерялось фотометрическим методом, основанным на образовании синего цвета комплекса Ala c ионами $\mathrm{Cu}^{2+}$ [3]. Концентрация катионов натрия измерялась методом пламенно-эмиссионной фотометрии [4].

\section{Обсуждение результатов}

В работе рассматривалась электромембранная система, содержащая смешанные растворы неорганической соли и аминокислоты, моделирующие растворы стадии деминерализации при получении нейтральных аминокислот с различным боковым радикалом. На рисунке 2 показаны вольт-амперные кривые катионообменной мембраны МК-40, зарегистрированные при электродиализе 
растворов исследуемых аминокислот и хлорида натрия, а также в индивидуальном растворе минеральной соли. В растворе, содержащем аминокислоту, наблюдаются изменения параметров BAX MК-40 по сравнению с BAX мембраны в растворе $\mathrm{NaCl}$. Зафиксировано сокращение длины участка ВАХ, соответствующего протеканию реакции диссоциации воды на межфазной границе катионообменная мембранараствор, и увеличение угла наклона «плато», связанное с увеличением гидрофобности поверхности мембраны из-за адсорбции аминокислоты, проявляющей гидрофобные свойства. С ростом гидрофобных свойств поверхности мембраны увеличивается электроконвекция [5,6]. Согласно [7] наибольшей гидрофобностью из исследуемых аминокислот обладает триптофан ввиду наличия гетероциклического кольца в его структуре, наименьшей - алифатическая аминокислота аланин. С увеличением гидрофобных свойств аминокислоты растет вклад электроконвективного перемешивания раствора в интенсивных токовых режимах. Уменьшение длины «плато» ВАХ мембраны МК-40 в растворе аминокислоты и хлорида натрия по сравнению с индивидуальным раствором минеральной соли связано с большим количеством переносчиков тока в смешанном растворе. Присутствие при данной концентрации аминокислоты в растворе незначительно увеличивает величину предельного тока, определяемого из ВАХ мембраны по перепендикуляру, опущенному на ось ординат из точки пересечения касательных линий, проведенных к 1 и 2 участку ВАХ. В интенсивном токовом режиме ( участок 3 BAX) ввиду накопления переносчиков тока наблюдается монотонное увеличение напряжения на мембране в зависимости от величины заданной плотности тока. Участки BAX мембраны показаны на рисунке 2 для раствора $\operatorname{Trp}(0.02 \mathrm{M})+\mathrm{NaCl}(0.01 \mathrm{M})$.

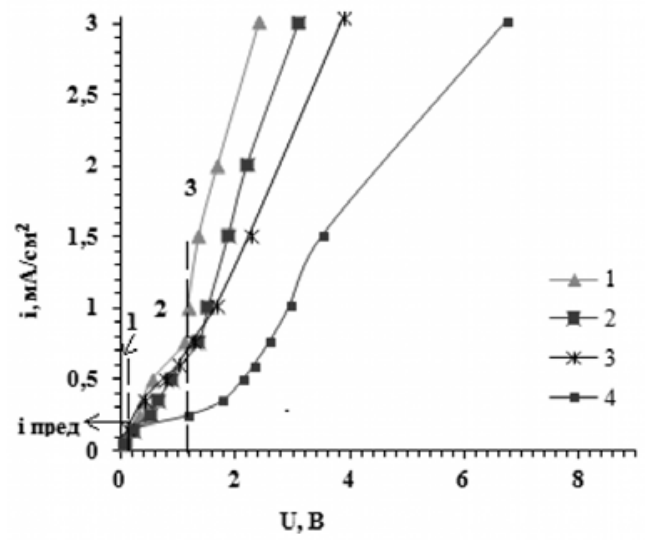

Рис. 2. ВАХ катионообменной мембраны МК-40 при электродиализе растворов: $1-\operatorname{Trp}+\mathrm{NaCl}, 2-\mathrm{Phe}+\mathrm{NaCl}, 3-\mathrm{Ala}+$ $\mathrm{NaCl}, 4-\mathrm{NaCl}$

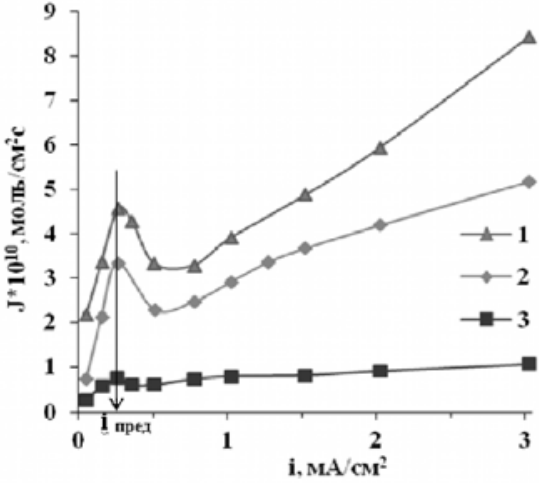

Рис. 3. Зависимость потоков аминокислот через мембрану МК-40 при электродиализе растворов: 1 - Ala $+\mathrm{NaCl}$, $2-\mathrm{Phe}+\mathrm{NaCl}, 3-\mathrm{Trp}+\mathrm{NaCl}$ от плотности тока

При исследовании потоков аминокислот, отличающихся строением бокового радикала, через катионообменную мембрану МК-40 в зависимости от плотности тока при электродиализе смешанных растворов выявлено увеличение массопереноса аминокислот в исследованном диапазоне плотностей тока с уменьшением ее молекулярной массы и увеличением подвижности (рисунок 3). Потоки аланина максимальны среди рассмотренных аминокислот, потоки триптофана минимальны. 
Специфическая форма потоков аминокислоты от плотности тока с максимумом, достигаемым при предельном токе, связана с изменением соотношения ионных форм аминокислоты в растворе в зависимости от показателя кислотности среды, который изменяется ввиду протекания реакции разложения воды на межфазной границе мембрана-раствор. В результате действия таких эффектов как барьерный [8] и эффект облегченной электромиграции $[9,10]$ наблюдается нелинейная зависимость потоков органических амфолитов от плотности тока.

Выявленные по максимуму зависимостей потоков аминокислот через мембрану МК-40 от плотности тока значения предельной плотности тока близки к значениям предельной плотности тока, определенным из ВАХ мембраны.

Неотъемлемая часть исследования особенностей деминерализации растворов аминокислот состоит в контроле потоков ионов минеральной соли через ионообменные мембраны от плотности тока. В процессе электродиализа растворов хлорида натрия, содержащих аминокислоты (триптофан, аланин или фенилаланин), выявлено различие потоков катионов натрия при плотностях тока выше $0.5 \mathrm{~mA} / \mathrm{cm}^{2}$ (рис.4).

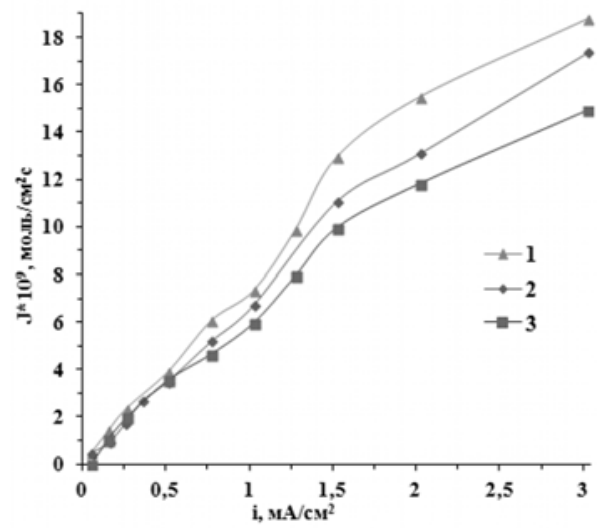

Рис. 4. Зависимость потоков катионов натрия через катионообменную мембрану МК-40 от плотности тока при электродиализе растворов: $1-\mathrm{Phe}+\mathrm{NaCl}$,

$$
2-\operatorname{Trp}+\mathrm{NaCl}, 3-\mathrm{Ala}+\mathrm{NaCl}
$$

Максимальные потоки аланина через катионообменную мембрану среди рассматриваемых аминокислот (рис.3) сопровождаются минимальными потоками катионов натрия из смешанного раствора с данной аминокислотой в интенсивном токовом режиме. Поток ионов $\mathrm{Na}^{+}$через катионообменную мембрану в присутствии фенилаланина при сверхпредельных токах достигает наибольших значений. Потоки катионов соли имеют промежуточные значения в присутствии триптофана. Несмотря на малый массоперенос триптофана через МК-40, большой объем данной аминокислоты ограничивает транспорт катионов натрия сильнее, чем в случае фенилаланина.

Ввиду существенного влияния $\mathrm{pH}$ на ионный состав растворов аминокислоты в работе исследовано изменение показателя кислотности среды секций обессоливания и концентрирования со стороны мембраны МК-40 с ростом плотности тока (рис. 5). На зависимости $\mathrm{pH}$ растворов секции обессоливания (4) от плотности тока имеется небольшой максимум (рисунок 5а)), связанный с различными величинами предельного тока, достигаемого на катионообменной и анионообменной мембране. Это происходит из-за различия в подвижности катионов натрия и ионов хлора в растворе.

Значения плотности тока, при которых начинается резкое снижение $\mathrm{pH}$ растворов секции концентрирования со стороны мембраны МК-40 (рисунок 5б) при 
электродиализе смешанных растворов соли и аминокислоты с использованием методики несимметричной поляризации, несколько выше по сравнению со значениями предельной плотности тока, определенными из ВАХ мембраны, а также из зависимостей потоков аминокислоты (J(AК)) от плотности тока по их максимуму.

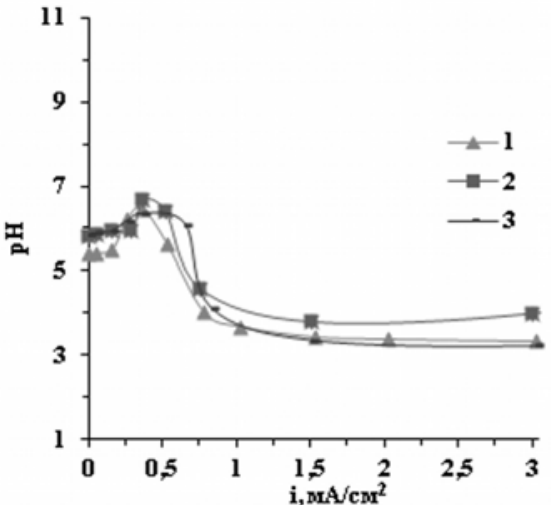

a

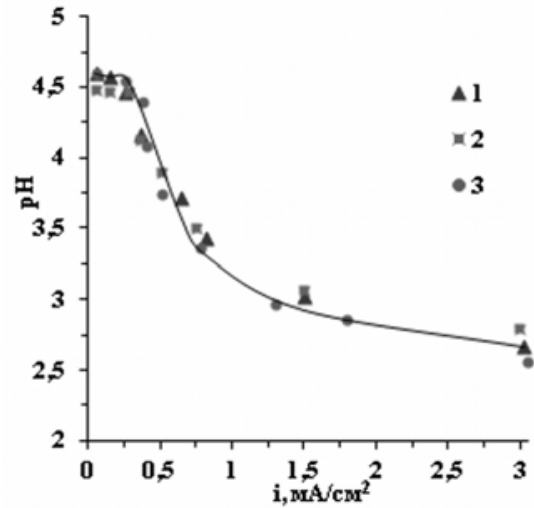

6

Рис. 5. Зависимость показателя кислотности среды растворов камеры деионизации (а), камеры концентрирования со стороны мембраны МК-40 (б) от плотности тока в процессе электродиализа растворов:

$$
1-\operatorname{Trp}+\mathrm{NaCl}, 2-\mathrm{Ala}+\mathrm{NaCl}, 3-\mathrm{Phe}+\mathrm{NaCl}
$$

Достижение предельного состояния на катионообменной мембране МК-40 в растворе хлорида натрия, определенного из ВАХ мембраны, наблюдается при $\mathrm{i}_{\text {пред. эксп }}=0.18 \mathrm{MA} / \mathrm{cm}^{2}$. Теоретически рассчитанное значение предельной плотности тока для мембраны МК-40 в растворе хлорида натрия составило $0.17 \mathrm{~mA} / \mathrm{cm}^{2}$. Расчет проводился при учете таких параметров электромембранной системы как длина канала обессоливания $(L)$, концентрация электролита на входе в канал $\left(\mathrm{c}_{\mathrm{in}}\right)$, расстояния между мембранами $(h)$, средней линейной скорости течения раствора $(\bar{v})$, а также физико-химических характеристик ионов: числа переноса противоионов в мембране $(\bar{t})$ и в растворе $(t)$, коэффициента диффузии противоионов электролита (D) с использованием формулы Левека (1):

$$
\mathrm{i}_{\text {пред }}=1.47 \frac{F D c_{\text {in }}}{h(\bar{t}-t)}\left(\frac{h^{2} \bar{v}}{L D}\right)^{\frac{1}{3}}
$$

Значения предельной плотности тока, достигаемые на катионообменной мембране МК-40, определенные из ВАХ мембраны (i пред $\left.{ }^{*}\right)$, по зависимостям J(АК) - i $\left(\mathrm{i}_{\text {пред }}{ }^{* *}\right)$, по началу резкого снижения $\mathrm{pH}$ в камере концентрирования 5 ( $\left.\mathrm{i}_{\text {пред }}{ }^{* *}\right)$, a также параметры ВАХ данной мембраны в растворах исследованных аминокислот в смеси с минеральной солью приведены в таблице 1.

Таблица 1. Значения предельной плотности тока, достигаемые на МК-40, и параметры «плато» вольт-амперных кривых данной мембраны

\begin{tabular}{|c|c|c|c|c|}
\hline Параметр & $\begin{array}{c}\mathrm{NaCl} \\
(0.01 \mathrm{M})\end{array}$ & $\begin{array}{c}\operatorname{Phe}(0.02 \mathrm{M})+ \\
\mathrm{NaCl}(0.01 \mathrm{M})\end{array}$ & $\begin{array}{c}\mathrm{Ala}(0.02 \mathrm{M})+ \\
\mathrm{NaCl}(0.01 \mathrm{M})\end{array}$ & $\begin{array}{c}\operatorname{Trp}(0.02 \mathrm{M})+ \\
\mathrm{NaCl}(0.01 \mathrm{M})\end{array}$ \\
\hline $\mathrm{i}_{\text {пред }}{ }^{*}, \mathrm{MA} / \mathrm{cm}^{2}$ & $0.18 \pm 0.02$ & $0.22 \pm 0.02$ & $0.21 \pm 0.02$ & $0.21 \pm 0.02$ \\
\hline $\mathrm{i}_{\text {пред }} * *, \mathrm{MA} / \mathrm{cm}^{2}$ & - & $0.22 \pm 0.02$ & $0.22 \pm 0.02$ & $0.22 \pm 0.02$ \\
\hline $\mathrm{i}_{\text {пред }} * * *, \mathrm{~mA} / \mathrm{cm}^{2}$ & $0.23 \pm 0.05$ & $0.25 \pm 0.05$ & $0.25 \pm 0.05$ & $0.25 \pm 0.05$ \\
\hline Длина «плато» $\mathrm{BAX}, \mathrm{B}$ & 1.93 & 1.01 & 1.05 & 0.98 \\
\hline $\operatorname{tg} \angle$ наклона «плато» $\mathrm{BAX}$ & 0.21 & 0.87 & 0.84 & 1.21 \\
\hline
\end{tabular}


Изменения параметров ВАХ мембраны МК-40, выявляемые при электродиализе растворов, содержащих аминокислоты, по сравнению с BAX катионообменной мембраны в индивидуальном растворе минеральной соли, обусловлены способностью амфолитов к перезарядке при отклонениях рН от изоэлектрической точки, а также изменением свойств поверхности мембраны, контактировавшей с растворами различных аминокислот. Природа аминокислоты оказывает влияние на ее массоперенос и на потоки ионов минеральной соли, на интенсивность протекания реакции диссоциации воды в запредельных условиях электродиализа, что выражается в уменьшении длины участка плато BAX, увеличении угла его наклона по сравнению с данными параметрами ВАХ в растворе хлорида натрия. В допредельных условиях электродиализа малая доля монополярных ионов аминокислоты не приводит к значительному изменению величины предельной плотности тока, достигаемой на мембране в индивидуальном растворе минеральной соли.

\section{Заключение}

Исследовано влияние природы бокового радикала аминокислот на их массоперенос и на транспорт катионов минеральной соли через катионообменную мембрану МК-40 из смешанных растворов органического амфолита и хлорида натрия. Адсорбция ионообменными мембранами аминокислот с более высокими гидрофобными свойствами в процессе электродиализа приводит к большему вкладу электроконвективной составляющей при массопереносе компонентов раствора через мембрану в интенсивном токовом режиме. В соответствии с ростом гидрофобности аминокислот в ряду: Ala $<$ Phe $<$ Trp длина плато BAX мембраны MК-40 снижается.

При электродиализе смешанных растворов аминокислоты и хлорида натрия природа бокового радикала и подвижность ионов аминокислоты влияют не только на ее поток, но и на массоперенос катионов минеральной соли через мембрану при сверхпредельных токах. Наличие аминокислоты в растворе хлорида натрия при используемой концентрации незначительно повышает величину предельной диффузинной плотности тока, достигаемой на катионообменной мембране. Значения предельной плотности тока, определенные из зависимостей $\mathrm{pH}$ (i), несколько больше

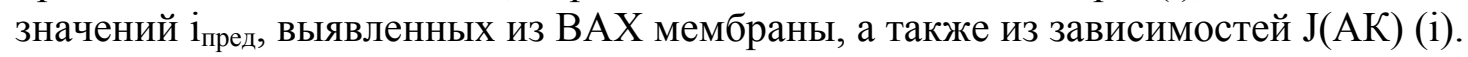

Результаты данного исследования могут быть использованы при разработке методик электромембранной деминерализации растворов аминокислот с различными боковыми радикалами.

Работа выполнена при финансовой поддержке «Фонда содействия развитию мальх форм предприятий в научно-технической сфере», программа «УМНИК» договор 10032ГУ2/2015.

\section{Список литературы}

1. Шапошник В.А. Кинетика электродиализа. Воронеж.. ВГУ. 1989. 176 с.

2. Котова Д.Л., Крысанова Т.А., Елисеева Т.В. Спектрофотометрическое определение аминокислот в водных растворах: учеб. Пособие. Воронеж. Изд-во Воронеж. ун-та. 2004. 54 c.
3. Рошаль Е.Р., Демина Н.Г., Шолин А.Ф., Румянцева Н.Ф. // Химикофармачевтический журнал. 1988. Т. 2. № 1. C. 30-37.

4. Основы аналитической химии. Практическое руководство. Под ред. Ю. А. Золотова. М. Высшая школа. 2003. 463 с. 
5. Nikonenko V.V., Pismenskaya N.D., Belova E.I., Sistat Ph. et al. // $A d v$. in Colloid and Interface Sci. 2010. Vol. 160. pp. 101-123.

6. Бугаков В.В., Заболоцкий В.И., Лебедев К.А., Никоненко В.В. и др. // Электрохимия. 2012. Т. 48. № 7. C.766-777.

7. Nozaki Y., Tanford C. // J. biol. chem. 1971. Vol. 246. No 7. pp. 2211-2217.

\section{References}

1. Shaposhnik V.A., Kinetika elektrodializa, Voronezh, VSU, 1989, 176p.

2. Kotova D.L., Krysanova T.A., Eliseeva T.V. Spektrofotometricheskoe opredelenie aminokislot $v$ vodnykh rastvorakh: uchebnoe posobie, Voronezh, Izd-vo Voronezh. un-ta, 2004, $54 \mathrm{p}$.

3. Roshal' E.R., Demina N.G., Sholin A.F., Rumyantseva N.F., Khimiko-farmatsevticheskii zhurnal, 1988, Vol. 2, No 1, pp. 30-37.

4. Osnovy analiticheskoi khimii. Prakticheskoe rukovodstvo. Ed. by Zolotov Yu. A. Moskva, Vysshaya shkola, 2003, 463p.

5. Nikonenko V.V., Pismenskaya N.D., Belova E I., Sistat Ph. et al., Adv. in Colloid and In-

Харина Анастасия Юрьевна - аспирант кафедры аналитической химии Воронежского государственного университета, Воронеж, тел. (4732) 20-89-32

Елисеева Татьяна Викторовна - к.х.н., доцент кафедры аналитической химии Воронежского государственного университета, Воронеж, тел. (4732) 20-89-32
8. Войтович И.М., Шапошник В.А., Котов В.В. // Теория и практика сорбционных проиессов. 1976. № 11. С. 106-108.

9. Шапошник В.А., Елисеева Т.В., Текучев А.Ю., Лущик И.Г. // Электрохимия. 2001. Т. 37. № 2. C. 195-201.

10. Елисеева Т.В., Шапошник В.А. // Электрохимия. 2000. Т. 36. № 1. С. 73-79.

terface Sci., 2010, Vol.160, pp. 101-123. DOI:10.1016/j.cis.2010.08.001

6. Bugakov V.V., Zabolotskiy V.I., Lebedev K.A., Nikonenko V.V. et al., Elektrokhimiya, 2012, Vol. 48, No 7, pp.766-777.

7. Nozaki Y., Tanford C., J. Biol. Chem., 1971, Vol. 246, No 7, pp. 2211-2217.

8. Voitovich I.M., Shaposhnik V.A., Kotov V.V., Teoriya i praktika sorbtsionnykh protsessov, 1976, No 11, pp. 106-108.

9. Shaposhnik V.A., Eliseeva T.V., Tekuchev A.Yu., Lushchik I.G., Elektrokhimiya, 2001, Vol. 37, No 2, pp. 195-201.

10. Eliseeva T. V, Shaposhnik V.A., Elektrokhimiya, 2000, Vol. 36, No 1, pp. 73-79.

Kharina Anastasiia Yu. - Post-graduate Student, Department of Analytical Chemistry, Voronezh State University, Voronezh,e-mail: aukharina@gmail.com

Eliseeva Tatiana V. - Associate Professor, Department of Analytical Chemistry, Voronezh State University, Voronezh, e-mail: tatyanaeliseeva@yandex.ru 